\title{
ARBORIZAÇÃO E ACESSIBILIDADE EM CALÇADA: COMENTÁRIOS SOBRE O DESLOCAMENTO ENTRE CAMPI DA UNIVERSIDADE FEDERAL FLUMINENSE
}

\author{
Fernanda Francisco da Silva ${ }^{1}$; Maria Ernestina Alves Fidelis ${ }^{2}$, Protasio Ferreira e Castro ${ }^{3}$
}

(recebido em 25.03.2010 e aceito para publicação em 15.09.2011)

\section{RESUMO}

Com o crescimento populacional e a aglomeração nos grandes centros, as cidades tendem a ter, em sua maioria, fluxos confusos e superlotados. Nesse momento, começam as disputas por espaços, ocorrendo com maior frequência quando a cidade não foi planejada. Este trabalho apresenta as condições das calçadas, quanto à arborização, entre Campi da Universidade Federal Fluminense, onde os alunos dos cursos de Engenharia precisam se deslocar do Campus da Praia Vermelha para assistirem aulas do ciclo básico no Campus do Valonguinho. É apresentada a importância da arborização urbana e os benefícios advindos da ocupação vegetal nas cidades, visando a preocupação com o fluxo e acessibilidade dos pedestres nas calçadas das grandes cidades. Apresenta também como compatibilizar pedestre e arborização urbana, a partir do planejamento urbano e de plantio de mudas nas calçadas, da escolha da espécie arbórea e da execução de obras.

Palavras-chave: Arborização urbana; Acessibilidade; Calçada.

\footnotetext{
1 Fernanda Francisco da Silva, Arquiteta, Pós-Graduação em Engenharia Civil pela Universidade Federal Fluminense - UFF, Niterói, RJ, fernandafranci@gmail.com

${ }^{2}$ Maria Ernestina Alves Fidelis, Engenheira Civil, Pós-Graduação em Engenharia Civil pela Universidade Federal Fluminense - UFF, Niterói, RJ, tinaalvesf@yahoo.com.br

3 Protasio Ferreira e Castro, PhD, Pró-Reitor de Pós-Graduação e Pesquisa da UNIGRANRIO, Programa de Pós-Graduação em Ensino de Ciências, Rio de Janeiro, RJ, pfcastro@oi.com.br
} 


\title{
URBAN FOREST AND ACCESSIBILITY ON SIDEWALK: COMMENTS ABOUT DISPLACEMENT BETWEEN CAMPI OF FEDERAL FLUMINENSE UNIVERSITY
}

\begin{abstract}
Due to increasing population and agglomeration in large centers, cities tend to have confused and overcrowded flows. Is in this scenery where begin disputes by spaces, mainly if the city was not planned. This study presents sidewalks conditions in relation to urban forest, that are located among Fluminense Federal University Campi, where engineering students need to move from Campus Praia Vermelha to Campus Valonguinho to attend basic cycle classes. The importance and benefits of urban forest in the cities, aiming the concern about flow and accessibility of pedestrians on sidewalks are presented. Also it is showed how to conciliate pedestrian and urban forest, from urban planning, tree planting on the sidewalks, choice of tree species and execution of works.
\end{abstract}

Keywords: Urban forest; Accessibility; Sidewalk.

\section{INTRODUÇÃO}

$\mathrm{Na}$ busca por melhores condições de vida, o resgate ao meio ambiente vem fazendo com que o homem junte esforços no sentido de recuperar a flora para the proporcionar uma melhor e harmoniosa vivência no ambiente construído. Com isso investe-se fortemente em novos plantios em diversas áreas das cidades. A arborização urbana é de grande importância para manter o ambiente urbano mais agradável e confortável, seja termicamente ou como purificação do ar local, além de contribuir para o embelezamento das cidades.

Entretanto, quando não há planejamento e se planta sem conhecimento ou controle, pode-se gerar grandes conflitos como, por exemplo, o mau funcionamento do fluxo e da acessibilidade dos pedestres. O sucesso da arborização nas áreas urbanas está ligado à

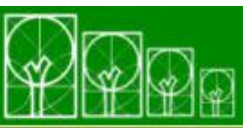

$\mathbf{S} \cdot \mathbf{B} \cdot \mathbf{A} \cdot \mathbf{U}$ Soc. Bras. de Arborização Urbana

REVSBAU, Piracicaba - SP, v.6, n.3, p.43-63, 2011 
quantidade, qualidade e distribuição da vegetação, fazendo com que o planejamento e o conhecimento sejam primordiais ao meio urbano.

Este trabalho apresenta as condições das calçadas no trajeto dos alunos da UFF do Campus da Praia Vermelha para o Campus do Valonguinho e os problemas causados pelo plantio não planejado nas calçadas. A falta de planejamento e o plantio inadequado de espécies podem gerar barreiras físicas e transtornos. Criam dificuldades para pedestres e principalmente para as pessoas com necessidades especiais, que utilizam o equipamento urbano: calçada.

Por essa razão, o trabalho tem como foco o plantio desordenado de árvores nas calçadas das cidades, especialmente no trecho entre os Campi da Praia Vermelha e do Valonguinho na Universidade Federal Fluminense. Também caracteriza a ausência de planejamento e de estudo adequado para as calçadas, notadamente no sentido de garantir um equipamento urbano de trânsito seguro, confortável e livre de obstáculos para o pedestre.

\section{Arborização Urbana}

Arborização urbana é toda "cobertura vegetal arbórea existente na cidade". Essa vegetação ocupa áreas livres de uso público, como os parques e praças, áreas livres particulares, além de acompanhar o sistema viário (IBGE, 2004).

A arborização urbana diz respeito aos elementos vegetais de porte arbóreo, dentro da cidade. Nesse enfoque, as árvores plantadas em calçadas fazem parte da arborização urbana, porém não integram o sistema de áreas verdes.

Arborização urbana é o conjunto de terras públicas e particulares, com cobertura arbórea, que uma cidade apresenta (GREY; DENEKE,1978), além de exercer grande função ecológica, uma vez que traz como benefícios: purificação do ar, retenção da umidade do solo e do ar ao produzir sombra, evitando que os raios solares incidam diretamente sobre as pessoas, oferece abrigo à fauna, amortece os ruídos e ainda contribui para o embelezamento urbano, deixando o ambiente agradável para os transeuntes. Com relação à poluição, pode-se dizer que as árvores ajudam na retenção de poluentes, no consumo do gás carbônico e na produção de oxigênio e contribuem para a melhoria da qualidade do ar. Além disto, as cortinas vegetais são capazes de diminuir em cerca de $10 \%$ o teor de poeira

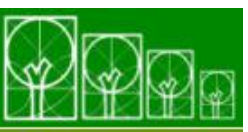

$\mathbf{S} \cdot \mathbf{B} \cdot \mathbf{A} \cdot \mathbf{U}$ Soc. Bras. de Arborização Urbana

REVSBAU, Piracicaba - SP, v.6, n.3, p.43-63, 2011 
e obstruir a propagação do som, resultando na redução do nível de ruído (AZEVEDO; GONÇALVES, 2010).

Os problemas da arborização urbana estão relacionados aos aspectos locais como: fiação elétrica, encanamentos, tipo de calçamento, quantidade de postes de iluminação, espaço disponível, equipamentos urbanos encontrados, largura da calçada e recuo predial. Para que a arborização traga apenas benefícios é importante que haja um planejamento da arborização urbana e conhecimento das seguintes leis:

- Lei 7.803/89, alterando a Lei 4.771/65 que estabelece o Código Florestal Brasileiro;

- Lei 6.766/79 que dispõe sobre parcelamento do solo urbano;

- Lei Orgânica do Município;

- Plano Diretor do Município e leis complementares, como Código Municipal de Meio Ambiente;

- Lei Municipal de Parcelamento e Uso do Solo Urbano, Plano Viário Municipal;

- Lei do Mobiliário Urbano e Lei Municipal de Saneamento.

\section{Planejamento da Arborização Urbana}

O planejamento da arborização urbana descreve medidas que devem ser adotadas para sua adequada implantação. A Companhia Energética de Minas Gerais - Cemig, por exemplo, elaborou o Manual de Arborização (2001), que traz como etapas do planejamento da arborização: análise da vegetação e do local; conscientização da comunidade; arborização e componentes urbanos; escolha da espécie; compatibilização com ruas e calçadas, com áreas residenciais e com o sistema elétrico; cuidados e manutenção.

A análise da vegetação é importante para que sejam selecionadas espécies que se adaptem às condições do clima e do solo da região. A análise do local é necessária para que se faça a compatibilização da arborização com o sistema elétrico, abastecimento de água, esgotos, sinalizações e edificações. Além disso, devem ser consideradas as limitações, características do tráfego, largura das calçadas e ruas, tipo de ocupação e características ambientais. A Figura 1 mostra algumas distâncias a serem respeitadas para uma adequada arborização. 
Figura 1. Distâncias relativas

Figure 1. Relative distances

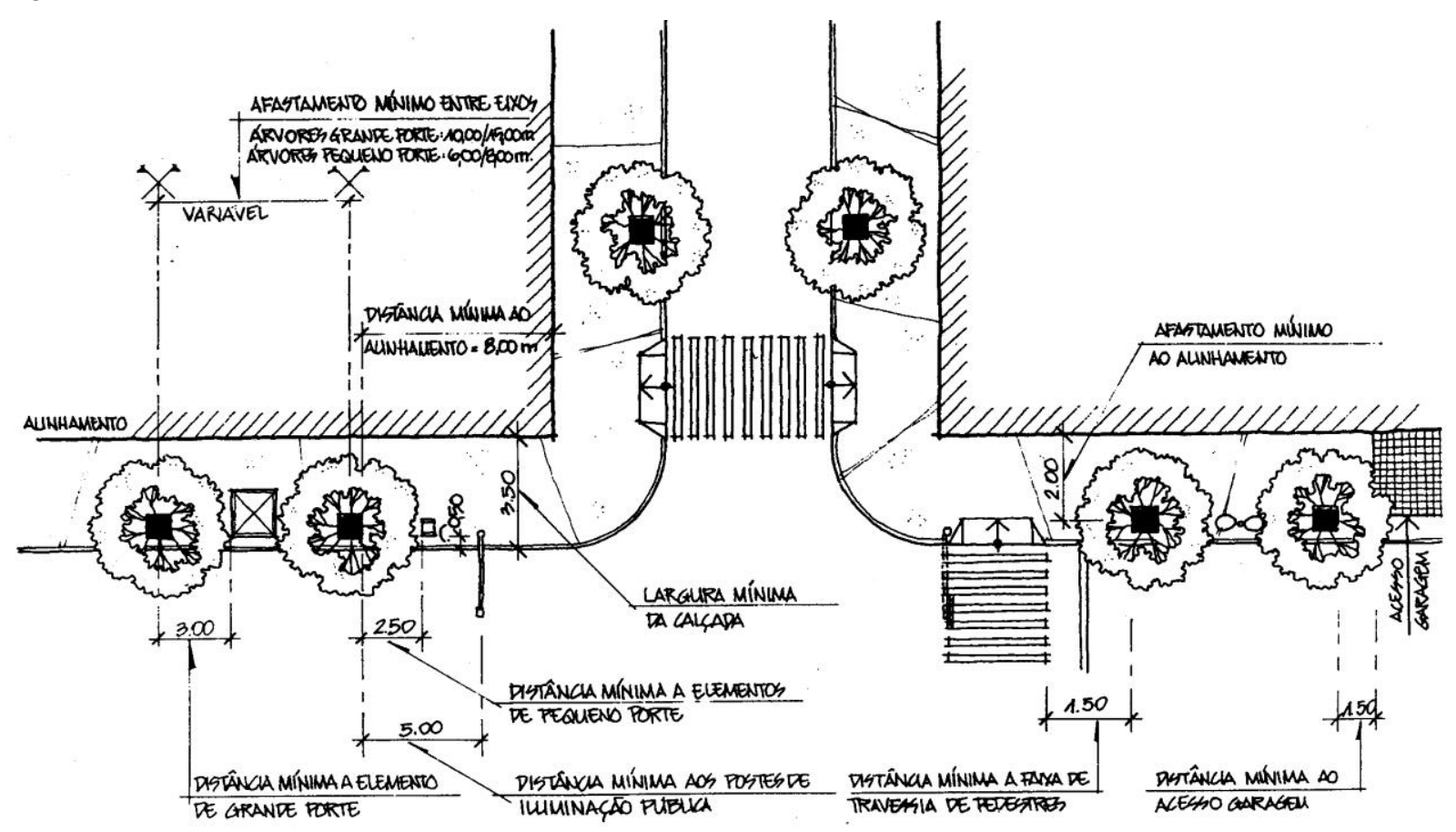

Fonte: Manual para Implantação de Mobiliário Urbano,1996, p.72.

Outro fator importante é a conscientização da população, aspecto que é essencial para se obter êxito na implantação e preservação das árvores. Essa conscientização deve ser realizada através de reuniões e palestras educativas. A arborização e componentes urbanos incluem o treinamento de uma equipe responsável pela implantação e manutenção das árvores, cadastramento de fornecedores de mudas ou implantação de um viveiro municipal.

A escolha da espécie deve ser feita de forma compatível com as condições locais como solo, clima, sistemas de saneamento, de telecomunicações e elétricos, sem causar problemas ao trânsito de pedestres e veículos. O manual da Cemig (2001) sugere que apenas uma espécie seja utilizada para cada rua ou para cada lado da rua, pois isso facilita o acompanhamento do desenvolvimento, o controle de pragas, doenças e as podas. Sugere também que sejam evitados: plantio de espécies com troncos com espinhos, árvores que dêem flores muito grandes e árvores frutíferas. Devem ser escolhidas espécies resistentes a pragas e doenças, com dimensões compatíveis com o espaço físico, permitindo o livre trânsito de veículos e pedestres, evitando danos aos transeuntes, às fachadas, calçadas e ruas e conflito com sinalização e iluminação. 
O manual da Cemig, no item compatibilização com ruas e calçadas diz que: ruas estreitas com passeios estreitos não devem ser arborizadas; em ruas estreitas com passeios largos e vice-versa devem ser plantadas espécies de médio e pequeno porte onde não houver fios; em ruas largas com passeios largos devem ser plantadas espécies de médio porte. A fundação Parque e Jardins e Norma Brasileiras de Acessibilidade a edificações, mobiliários, espaços e equipamentos urbanos - NBR 9050/2004 partilham das mesmas idéias e opiniões.

Tabela 1. Distâncias mínimas para plantio

Table 1. Minimum distances for planting

\begin{tabular}{l|l}
\hline Recuo mínimo da muda em relação ao meio-fio & $0,50 \mathrm{~m}$ \\
\hline Distâncias mínimas entre árvore e entradas de garagem & $1,00 \mathrm{~m}$ \\
\hline Vão livre entre a copa das árvores e a rede de baixa tensão & $1,00 \mathrm{~m}$ \\
\hline Vão livre entre a copa das árvores e a rede de alta tensão & $2,00 \mathrm{~m}$ \\
\hline Altura máxima das árvores de pequeno porte & $4,00 \mathrm{~m}$ \\
\hline Altura máxima das árvores de médio porte & $6,00 \mathrm{~m}$ \\
\hline Distância mínima entre árvores de pequeno porte e placas de sinalização & $5,00 \mathrm{~m}$ \\
\hline Distância mínima de árvores de médio porte e placas de sinalização & $7,00 \mathrm{~m}$ \\
\hline Distância mínima das esquinas & $7,00 \mathrm{~m}$ \\
\hline
\end{tabular}

Fonte: Ambiente Brasil, 2007.

\section{Escolha da Espécie}

O ambiente urbano se difere em vários itens do ambiente natural. Os solos, responsáveis pelo suporte físico das árvores e pelo substrato nutritivo do qual depende seu desenvolvimento, apresentam-se compactados nas cidades devido ao grande número de pavimentações que não permitem o escoamento das águas. Resíduos sólidos, despejos residenciais e industriais poluem e comprometem o solo urbano. A qualidade do ar fica comprometida pela combustão de veículos automotores e pela emissão de poluentes de indústrias. A arborização urbana traz benefícios como diminuição da poluição sonora, sombreamento, absorção da poluição atmosférica e de raios solares, entre outros.

As espécies utilizadas na arborização de ruas devem ser tecnicamente selecionadas. Comparado ao ambiente urbano, fatores como porte, tipo e diâmetro de copa, ocorrem de maneira diferente de um ambiente como uma mata natural. Na escolha de espécies deve-se 
considerar também fatores como adaptabilidade, sobrevivência e desenvolvimento no local de plantio.

Para facilitar o acompanhamento, desenvolvimento e as podas de formação e contenção, aconselha-se o plantio de apenas uma espécie para cada rua ou para cada lado da rua. Espécies com troncos que tenham espinhos também devem ser evitadas.

A espécie a ser utilizada depende também do local a ser arborizado. Em cidades de clima frio, é importante que se escolham espécies caducifólias, pois esse tipo perde as folhas em determinada época do ano, o que favorece o aproveitamento do calor solar nos dias frios. Em outros locais as espécies de folhagem perene são mais adequadas.

A dimensão da árvore deve ser compatível com o espaço físico, permitindo o livre trânsito de veículos e pedestres. Nas calçadas devem-se plantar apenas espécies com sistema radicular pivotante, cujo sistema de enraizamento seja profundo para evitar o levantamento e a destruição de calçadas e vias.

Devem-se selecionar, preferencialmente, espécies que não dêem flores ou frutos muito grandes; espécies rústicas e resistentes a pragas e doenças, pois não é aconselhável o uso de fungicidas e inseticidas no meio urbano; espécies de crescimento rápido, pois no ambiente urbano estão muito sujeitas à predação, sobretudo quando ainda pequenas. Podem-se utilizar espécies nativas ou espécies exóticas, observados os critérios citados e as características das espécies. Algumas espécies apresentam limitações para arborização urbana, por isso não são recomendadas.

\section{Conceitos}

\section{- CALÇADA}

A NBR 9284/1986 define calçada como: equipamento urbano de utilização pública ou privada destinada a prestação de serviços necessários ao funcionamento da cidade.

A NB 1338/1990 define passeio como: parte da via pública adjacente e paralela aos imóveis existentes em ambos os lados do leito carroçável, limitada pelo alinhamento destes e pelo meio-fio. Destinado fundamentalmente ao trânsito de pessoas e deve possuir as condições para o deslocamento adequado dos deficientes físicos.

A NBR 9050 de 2004 classifica calçada como: parte da via, normalmente segregada e em nível diferente, não destinada à circulação de veículos, reservada ao trânsito de pedestre e, quando possível, à implantação de mobiliário, sinalização, vegetação e outros 
fins. A Figura 2 apresenta as dimensões adequadas da calçada quanto à arborização e acessibilidade.

Figura 2. Arborização e acessibilidade.

Figure 2. Urban forest and accessibility.

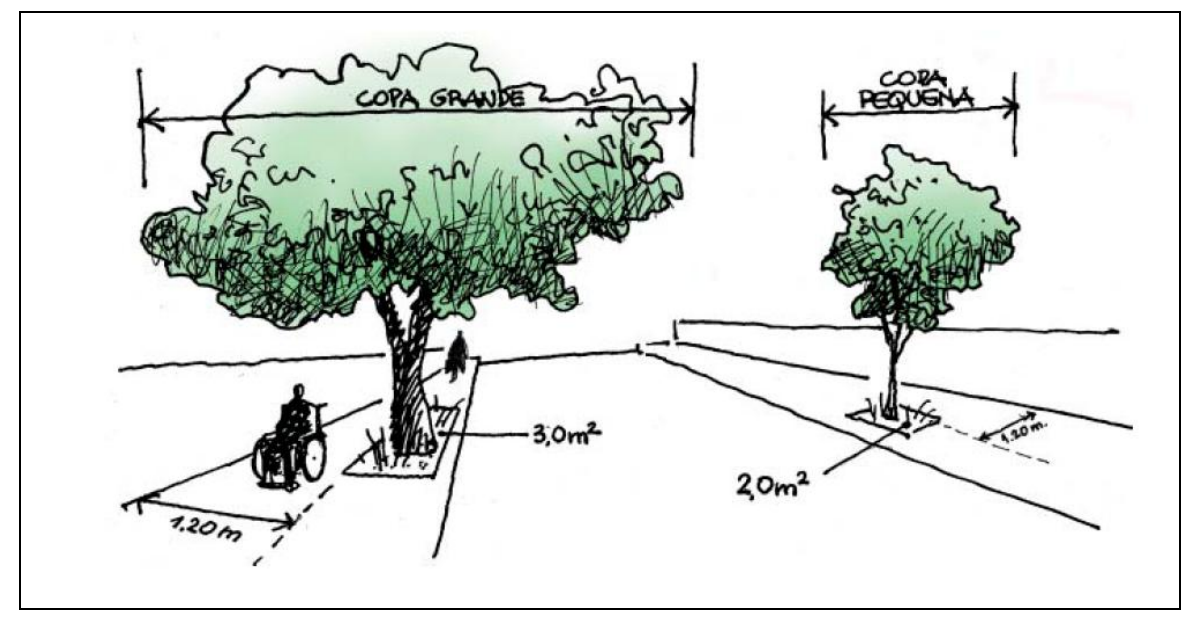

Fonte: Manual Técnico de Arborização Urbana, 2005, p.7.

\section{- MEIO AMBIENTE}

O Conselho Nacional do Meio Ambiente - CONAMA em sua resolução 306/2002 define Meio Ambiente como: conjunto de condições, leis, influência e interações de ordem física, química, biológica, social, cultural e urbanística, que permite, abriga e rege a vida em todas as suas formas.

Já, a ISO 14001/2004, define Meio Ambiente da seguinte maneira: circunvizinhança em que uma organização opera, incluindo-se ar, água, solo, recurso naturais, flora, fauna, seres humanos e suas inter-relações.

A Constituição Federal em seu artigo 225, diz:

Todos têm direito ao meio ambiente ecologicamente equilibrado, bem de uso comum do povo e essencial à qualidade de vida impondo-se ao Poder público e à coletividade o dever de defendê-lo e preservá-lo para as presentes e futuras gerações (Constituição Federal, Art. 225,1988).

A preservação do meio ambiente é responsabilidade de todos os seres humanos. É preciso agir com cautela e planejamento, e não de forma negativa e predatória, prejudicando a qualidade de vida no ambiente ocupado pelo homem. 


\section{Acessibilidade Urbana}

A acessibilidade é definida, segundo o Decreto $n^{\circ} 5296 / 2004$, como:

...condição para utilização, com segurança e autonomia, total ou assistida, dos espaços, mobiliários e equipamentos urbanos, das edificações, dos serviços de transporte e dos dispositivos, sistemas e meios de comunicação e informação, por pessoa portadora de deficiência ou com mobilidade reduzida (Decreto n5286, 2004).

As precárias condições de acessibilidade nas ruas e calçada são vistas em diversas cidades brasileiras, o que afeta grande parte da população, principalmente as pessoas com necessidades especiais. A questão da mobilidade agrava-se quando não se tem planejamento urbano e quando há conflito entre mobiliário urbano e pedestre ou equipamento urbano e pedestre, intensificando a disputa entre espaços e fluxos.

A Organização das Nações Unidas (ONU) estima que nos países em desenvolvimento, aproximadamente $10 \%$ da população são constituídas por pessoas com algum tipo de deficiência. O Instituto Brasileiro de Geografia e Estatísticas (IBGE, 2000) apontam como deficientes $14,5 \%$ da população brasileira. Muitas vezes a deficiência é fruto de acidentes causados pela falta do planejamento do espaço urbano.

A acessibilidade para pessoas com deficiência ainda é muito precária. Praças sem rampas, calçadas estreitas e em mau estado de conservação, desordenamento urbano e plantios inadequados são alguns dos fatores que implicam na acessibilidade não só das pessoas com deficiência e idosos, mas na vida de qualquer cidadão. A acessibilidade urbana é de suma importância para os que vivem e precisam circular no meio urbano. $A$ acessibilidade é um direito garantido em Lei. O incentivo ao plantio deve ser acompanhado de orientações sobre a espécie, porte arbóreo e tamanho da calçada. A arborização deve ser conduzida com planejamento adequado para que erros e conflitos sejam os menores possíveis.

Segundo a NB1338/1990 os passeios devem seguir as seguintes condições para utilização: ter dimensões mínimas, principalmente a largura mínima, para que todo e qualquer mobiliário ou vegetação urbana, instalado no passeio, não prejudique a locomoção e o lazer seguro das pessoas, assim como evite a utilização danosa à circulação. A largura mínima dos passeios, visando à utilização, é feita em função das condições locais.

A Constituição Federal Brasileira de 1988 estabelece o direito à cidade, fazendo-se da acessibilidade no ambiente urbano um direito garantido e faz com que todo e qualquer ambiente propicie ao cidadão na sua diversidade de condições físicas e sociais. O espaço urbano assim com as calçadas deve oferecer garantia ao acesso com segurança e conforto 
aos mais variados locais, como ao trabalho, aos locais de ensino, ao transporte, à cultura e ao esporte e lazer.

O Decreto Federal $n^{\circ}$. 3.298/1999, regulamenta Lei $n^{\circ}$. 7.853/1989 e dispõe sobre a Política para a Integração da Pessoa Portadora de Deficiência, consolida as normas de proteção, e dá outras providências. Desta forma garante as Pessoas com necessidades especiais direitos essenciais.

A Lei 10.098/2000 estabelece normas gerais e critérios básicos para a promoção da acessibilidade das pessoas portadoras de deficiência ou com mobilidade reduzida, e dá outras providências, como autonomia e constitui importante ferramenta para a promoção da acessibilidade no ambiente construído.

\section{Conceito de Acessibilidade}

As condições precárias de ruas, calçadas e a "desordem" urbana muitas vezes nos deixam indefesos e sem acessibilidade. Deficiência é o produto da interação entre inúmeras variáveis sociais e espaciais.

Segundo a Associação de Normas Técnicas - ANBT, "Acessibilidade é a possibilidade de condição de alcance, percepção e entendimento para a utilização com segurança e autonomia de edificações, espaço, mobiliário, equipamento urbano e elementos".

A ONU em sua resolução $n^{\circ} 217$, da Declaração dos direitos humanos, de dezembro de 1948, determina como acessibilidade: O ideal comum de ser atingido por todos os povos e todas as nações, com objetivo de que cada indivíduo e cada órgão da sociedade se esforce, através do ensino e da educação para promove o respeito aos direitos e liberdades, e adoção de medidas progressivas de caráter nacional e internacional, por assegurar o seu reconhecimento e a sua observância universal e efetiva, tanto entre povos dos próprios Estados-Membros, quanto entre os povos dos territórios sob sua jurisdição.

\section{Tipos de Acessibilidade}

A acessibilidade pode ser implementada em seis dimensões: arquitetônica, comunicacional, metodológica, instrumental, programática e atitudinal. Assim é que:

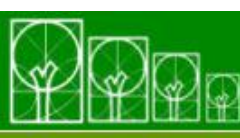


- A acessibilidade arquitetônica está ligada à eliminação de barreiras ambientais físicas em qualquer local e nos transportes coletivos;

- A acessibilidade comunicacional refere-se à eliminação de barreiras na comunicação interpessoal (face-a-face, língua de sinais, linguagem corporal, linguagem gestual, etc.), na comunicação escrita (jornal, revista, etc.) e na comunicação virtual (acessibilidade digital);

- A acessibilidade metodológica busca a eliminação de barreiras nos métodos e técnicas de estudo, de ação comunitária (metodologia social, cultural, etc.) e de educação dos filhos (novos métodos e técnicas nas relações familiares);

- A acessibilidade instrumental está associada a barreiras existentes nos instrumentos de atividades da vida diária e de lazer, esporte e recreação (dispositivos que atendam às limitações sensoriais, físicas e mentais, etc.);

- A acessibilidade programática tem a finalidade de eliminar barreiras invisíveis embutidas em políticas públicas em regulamentos e em normas em geral;

- A acessibilidade atitudinal acontece por meio de programas e práticas de sensibilização e de conscientização das pessoas em geral e da convivência na diversidade humana resultando em quebra de preconceitos, estigmas, estereótipos e discriminações (Nakayama, 2007).

\section{Desenho Universal}

O desenho universal é uma concepção que visa oferecer as mesmas condições de uso de mobiliário e espaço aos mais diversos tipos de pessoas. Criado por uma comissão em Washington, EUA em 1963, tem como objetivo considerar a diversidade humana e garantir acessibilidade a todos os ambientes.

A NBR 9050/2004 define Desenho Universal como: "Aquele que visa atender à maior gama de variações possíveis das características antropométricas e sensoriais da população".

O Desenho Universal deve seguir os seguintes princípios básicos: uso equiparável, flexibilidade no uso, uso simples e intuitivo, informação perceptível, tolerância ao erro, baixo esforço físico, tamanho e espaço para aproximação e uso. Os espaços devem ser projetados de forma a promover a inclusão e a utilização por qualquer pessoa com autonomia e segurança.

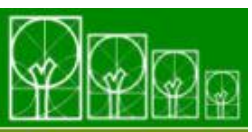

$\mathbf{S} \cdot \mathbf{B} \cdot \mathbf{A} \cdot \mathbf{U}$ Soc. Bras. de Arborização Urbana 


\section{Cenário Urbano}

O cenário atual de diversas cidades brasileiras é formado por congestionamentos crônicos, queda da mobilidade e da acessibilidade, degradação do meio ambiente, altos índices de acidentes de trânsito, além do uso excessivo do transporte individual. Devido a esses fatores, as cidades precisam ser planejadas priorizando a sustentabilidade e racionalidade da mobilidade, enfocando o transporte alternativo, a fim de proporcionar deslocamentos seguros e promover a melhoria da qualidade de vida.

A Figura 3, elaborada com base na tabela "Transporte Urbano e Metropolitano de Pessoas no Brasil" de Holanda (2006), mostra dados do transporte no Brasil, referente ao ano de 2002, dos quais mais da metade dos 200 milhões de deslocamentos que acontecem diariamente é feita a pé ou por bicicletas, enquanto que $60 \%$ das viagens motorizadas são realizadas por transporte público coletivo (IPEA (2003), apud Holanda (2006)). A incompatibilidade do ambiente construído juntamente com questões como insuficiência de educação e fiscalização do trânsito, fazem de pedestres e ciclistas os mais vulneráveis no trânsito das cidades. As viagens a pé foram consideradas as com mais de 500 metros. As com motos, apenas para as de uso pessoal, não comercial. O público inclui, além dos ônibus, trens, metrôs e barcas. O automóvel inclui táxi.

Figura 3. Transporte urbano e metropolitano de pessoas no Brasil - divisão por modos, 2002 Figure 3. Urban and metropolitan transport of people in Brazil - Division by modes, 2002

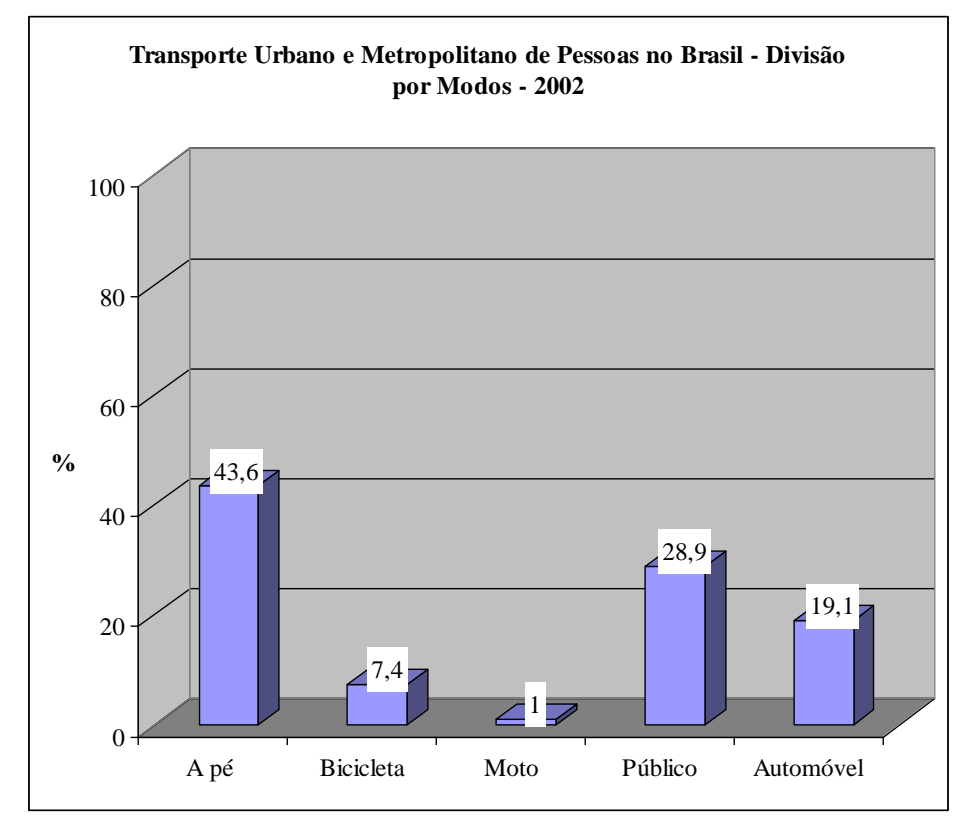

Fonte: Holanda, 2006, p.9.

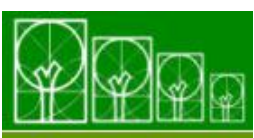




\section{Estudo de Caso}

Com a crescente concentração populacional nas áreas urbanas é necessário pensar de forma planejada na qualificação ambiental dos espaços na busca da melhoria do conforto térmico, acústico e do ar para essas áreas. A busca dessas benfeitorias pode ser feita através de plantio de árvores no ambiente urbano. Para o desenvolvimento das cidades é necessário que o meio ambiente e a sociedade caminhem juntos para um propósito comum que é o desenvolvimento com qualidade de vida.

Atualmente muitas cidades fazem plantio de mudas de árvores sem planejamento. Esse plantio sem controle, na maioria das vezes, gera transtornos para a população, como conflito no fluxo de pedestres e vegetação. Para o sucesso do ambiente construído é fundamental ter e seguir um planejamento urbano eficaz, onde seja favorecida a acessibilidade de pedestres e pessoas com deficiência. A adoção de medidas facilitadoras pode contribuir para a locomoção e a harmonia entre pedestres e meio ambiente.

Niterói, cidade com aproximadamente 487 mil habitantes (IBGE, 2010) é considerada a mais escolarizada do Estado, segundo dados da Prefeitura (2007). A UFF tem matriculado em seus cursos de graduação cerca de 29 mil alunos. Os alunos de alguns cursos necessitam locomover-se entre campi para terem aulas específicas. Grande parte do trajeto apresenta calçadas fora dos padrões de acessibilidade para pessoas com deficiência.

A construção de calçadas deve atender a Norma Brasileira Regulamentadora - NBR 9050/2004 e promover a justiça e igualdade das diversidades humanas existentes. O uso de materiais e equipamentos que promovam a acessibilidade também deve ser adotado, como utilização de pisos específicos, sinalização própria que assegure a acessibilidade com segurança e conforto. Em caso de plantio deverá ser utilizada gola de árvore a fim de alertar aos pedestres, principalmente pessoas com baixa visão e deficientes visuais. É significante a colaboração da arborização no meio urbano, principalmente nos grandes centros. Além de melhorar a questão da paisagem traz benefícios para a saúde e bem estar do homem na sociedade.

Um projeto de arborização deve levar em conta os seguintes fatores: o local e sua topografia, o entorno, as fachadas das construções, a largura das ruas e calçadas, o ventos dominantes, o percurso do sol e a respectiva visualização. Orienta-se que o plantio de árvores somente seja feito quando a calçada tiver largura igual ou superior a 3,50 m. 0 plantio de árvores de médio porte em calçadas deverá ter espaçamento mínimo de $6 \mathrm{~m}$, e 
para árvores de grande porte esse espaçamento deverá ser de $10 \mathrm{~m}$. Recomenda-se que as golas de árvores estejam próximas ao meio-fio.

É importante ter conhecimento das espécies arbóreas a serem utilizadas na arborização urbana, priorizando as espécies nativas do Brasil. A utilização de espécies não apropriadas acarreta em transtornos como danos em calçadas e conflito de galhos com a rede elétrica, podendo causar problemas maiores.

\section{Deslocamento entre Campi da Universidade Federal Fluminense}

Os alunos dos cursos de Engenharia da Universidade Federal Fluminense (UFF), precisam se deslocar do Campus da Praia Vermelha para assistirem aulas do ciclo básico no Campus do Valonguinho. Este trabalho mostra as condições da calçada, quanto à arborização e acessibilidade, no trajeto indicado no mapa (Figura 4). Foi considerado o menor trajeto entre os Campi, e apenas um lado da calçada (trajeto contínuo).

Figura 4. Mapa das calçadas entre Campi da UFF

Figure 4. Sidewalks map between UFF Campi

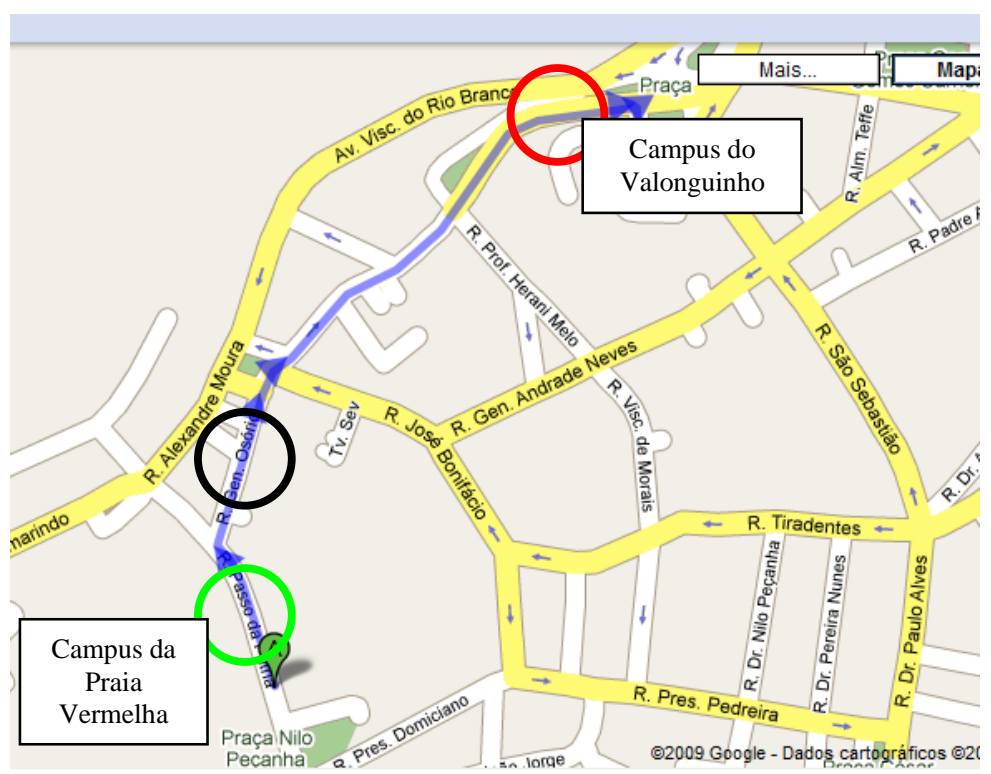

Fonte: Google maps.

As árvores existentes próximo ao Campus do Valonguinho (círculo vermelho da Figura 4) são Cassias (Senna siamea), árvores de médio a grande porte, têm gola e não impedem a passagem de pedestres conforme mostra a Figura 5. A calçada e o plantio foram 
planejados para dar maior segurança e conforto permitindo uma circulação adequada aos transeuntes. Não existem pisos táteis nas calçadas do trajeto entre o Campus do Valonguinho e Praia Vermelha.

Figura 5. Calçada em frente ao Campus do Valonguinho

Figure 5. Sidewalk in front of Valonguinho Campus

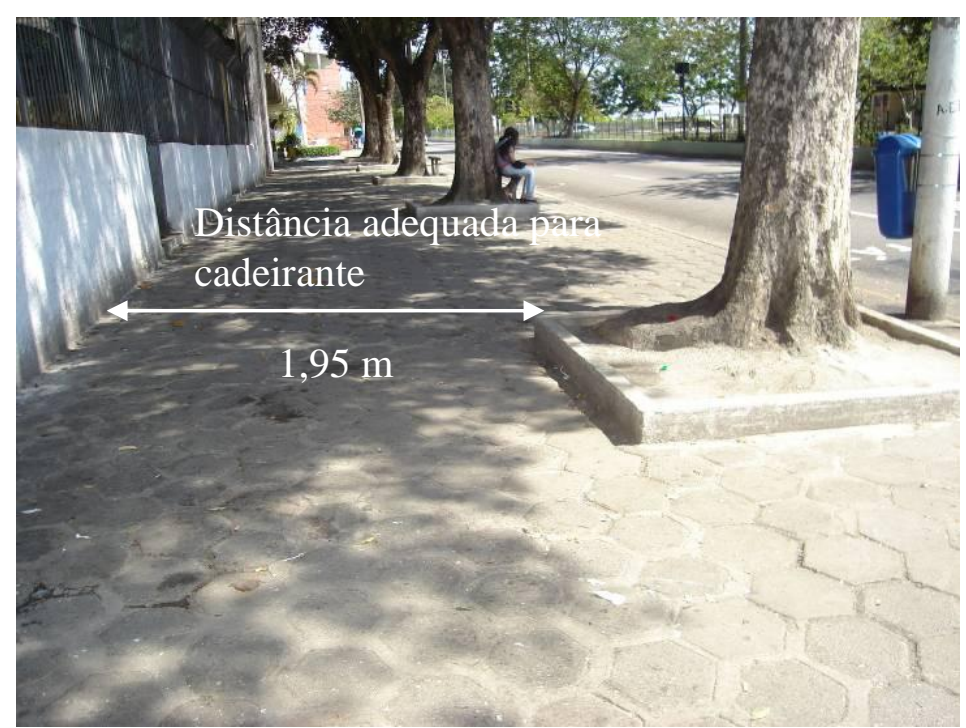

Fonte: Fidelis, 2009.

As demais árvores selecionadas para esse trabalho referem-se aos círculos preto e verde do mapa, presentes nas ruas General Osório (Figuras 6, 7 e 8) e Rua Passo da Pátria (Figura 9). Essas calçadas estão danificadas por raízes de árvores que se tornam obstáculos para os cadeirantes. 
Figura 6. Calçada da Rua General Osório

Figure 6. Sidewalk in General Osório Street

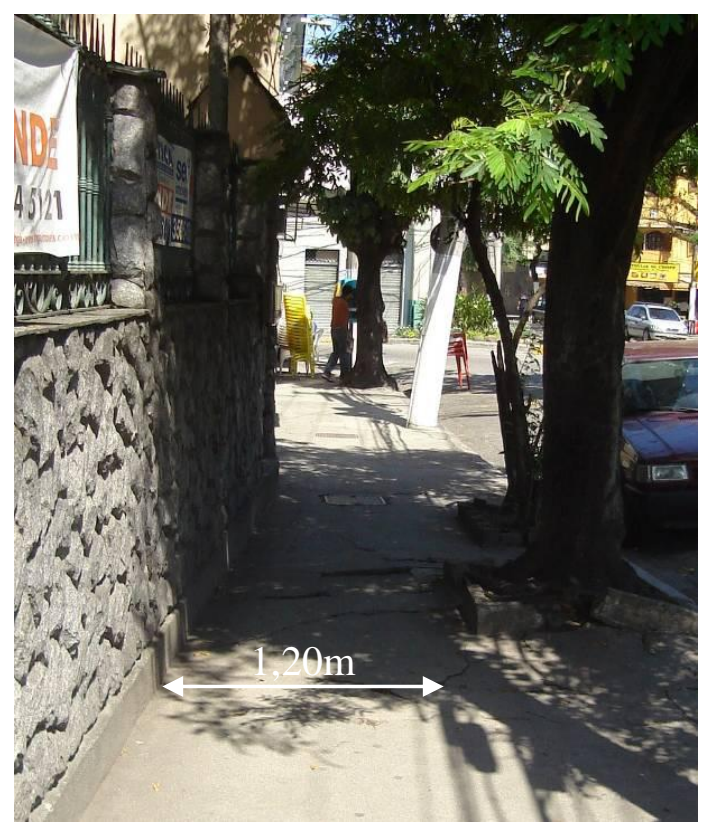

Fonte: Fidelis, 2009.

Algumas das árvores da Rua General Osório, mesmo sem gola, não impedem a circulação de pedestres. As Figuras 6 e 7 mostram a calçada danificada pela raiz e largura livre de 1,20 m, medida mínima recomendada pela NBR 9050/2004. A Figura 8, da mesma rua, mostra uma árvore nas mesmas condições.

Figura 7. Detalhe da Calçada da Figura 6

Figure 7. Sidewalk detail of Figure 6

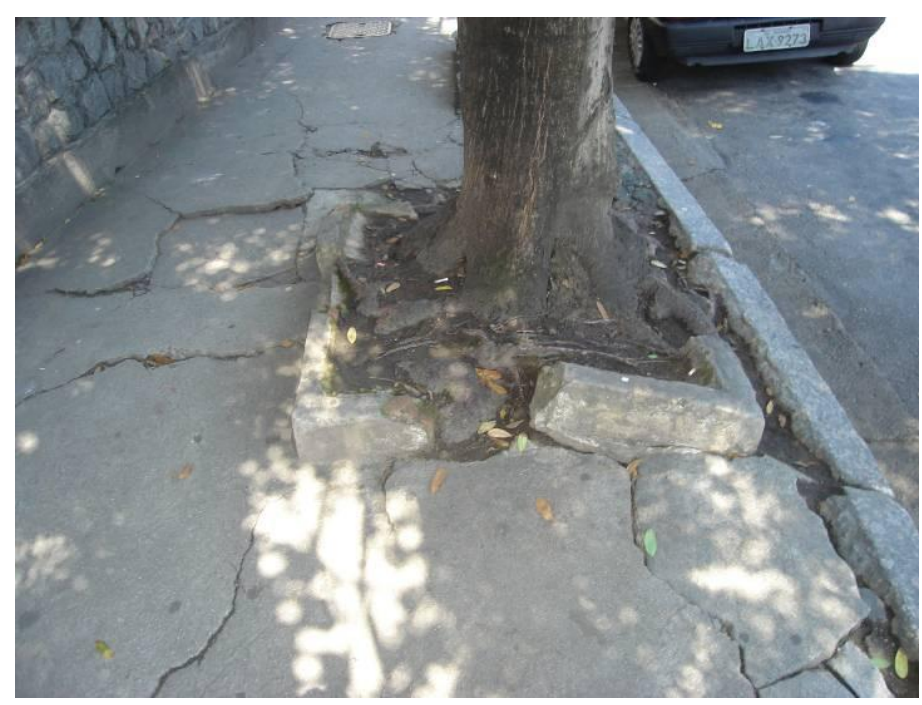

Fonte: Fidelis, 2009.

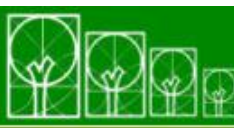

$\mathbf{S} \cdot \mathbf{B} \cdot \mathbf{A} \cdot \mathbf{U}$ Soc. Bras. de Arborização Urbana

REVSBAU, Piracicaba - SP, v.6, n.3, p.43-63, 2011 
Figura 8. Calçada da Rua Gen. Osório, próximo à Rua Passo da Pátria

Figure 8. Sidewalk in Gen. Osório Street, near Passo da Patria Street

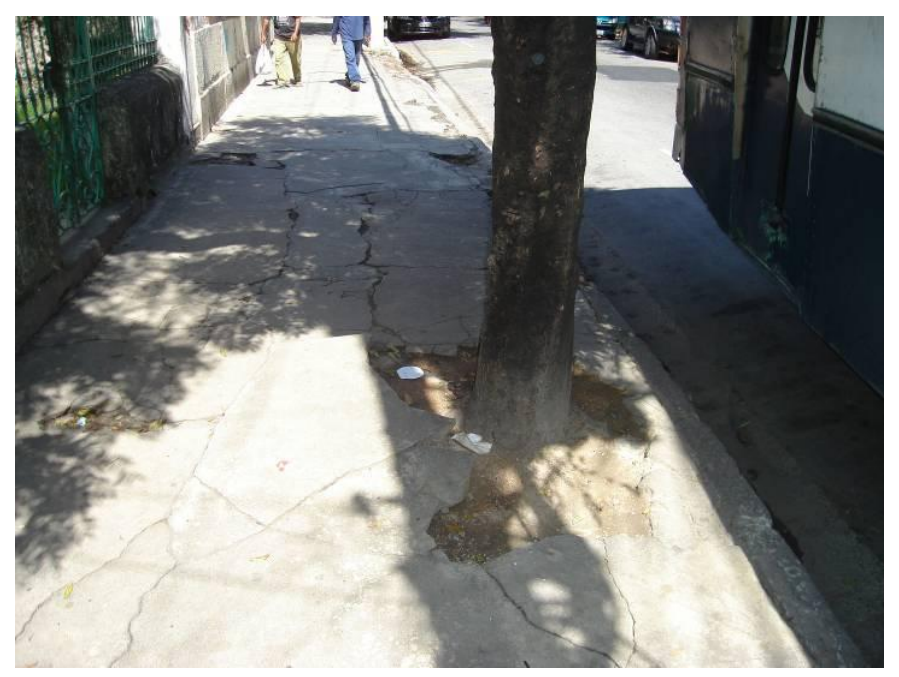

Fonte: Fidelis, 2009.

A Figura 9, da Rua Passo da Pátria, próximo ao Campus da Praia Vermelha, mostra árvore (Senna siamea) com gola, porém compromete a circulação de pedestres, deixando $1,00 \mathrm{~m}$ de largura livre.

Figura 9. Calçada da Rua Passo da Pátria - próximo ao Campus da Praia Vermelha Figure 9. Sidewalk in Passo da Pátria Street - near Praia Vermelha Campus

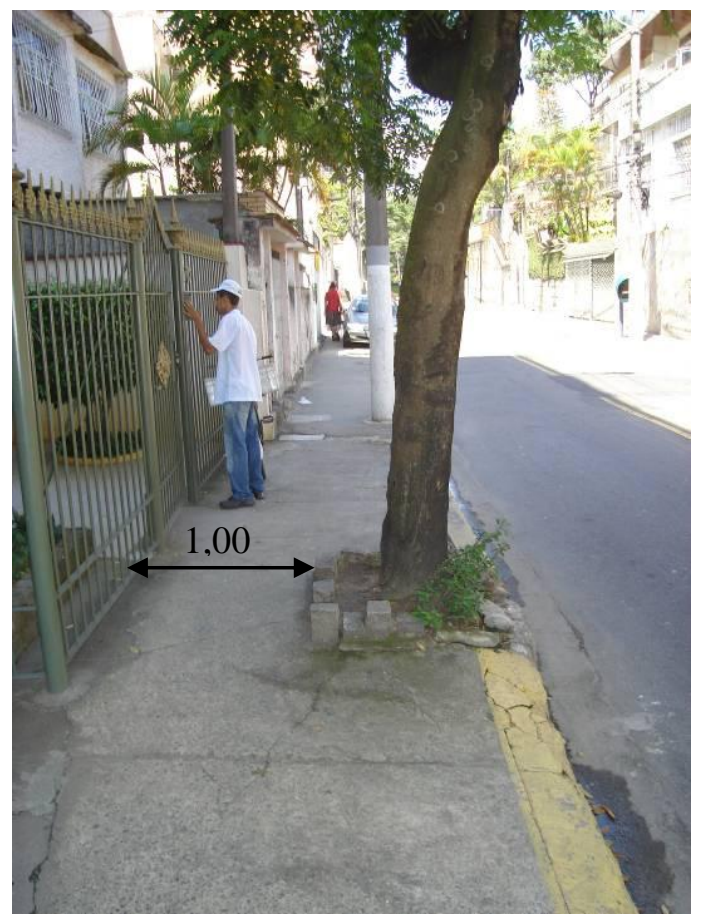

Fonte: Fidelis, 2009.

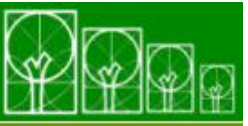


As árvores encontradas no trecho percorrido são na maioria da espécie Senna siamea, vulgarmente conhecida com Cassia. Por ter tronco ereto, sem espinhos e com pouca perda de folhas e frutos, essa espécie é comumente usada na arborização urbana pela Fundação Parques e Jardim no Rio de Janeiro. Também foi encontrada no trecho a espécie Terminallia catappa, popularmente conhecida como amendoeira.

\section{CONCLUSÃO}

Alguns trechos das calçadas entre os Campi da UFF apresentam problemas relacionados à arborização, devido à falta de gola nas árvores, espaço insuficiente para circulação de pedestres, danificação pelas raízes das árvores, etc. A largura livre da calçada deve ser de, no mínimo, 1,20 m. É necessário que se faça reparos nas calçadas em alguns trechos e, em outros, substituição de algumas espécies por outras de menor porte e construção de golas.

Como sugestão para prosseguimento do estudo, o mesmo pode ser direcionado para o desenvolvimento de um modelo estatístico de avaliação de calçadas de uma cidade. $O$ modelo poderia ser fundamentado em inspeções de trechos, obtidos por amostragem. $O$ modelo poderia avaliar a qualidade da calçada, quanto à existência de rampas, estado de conservação do pavimento, entre outros.

A falta de planejamento e conhecimento sobre o meio urbano e a vegetação adequada à arborização urbana, vem causando grandes transtornos para o uso com segurança das calçadas. A dificuldade em alguns casos não é somente para pessoas com deficiência, mas sim para todos os transeuntes que precisam e utilizam desse equipamento para se locomover.

Uma cidade segura e confortável é possível quando há planejamento e quando o mesmo é aplicado de forma contínua e permanente, destinado a resolver racionalmente os problemas que afetam a sociedade.

Atualmente as prefeituras têm se distanciado dos bairros residenciais deixando a cargo dos moradores locais a obrigação de cuidar de sua própria calçada. É necessário que haja planejamento da arborização para que todos possam exercer seu direito de locomoção com autonomia e segurança. É dever do Estado garantir esse direito. 


\section{AGRADECIMENTOS}

Os autores agradecem à Capes pela concessão da bolsa para realização da pesquisa.

\section{REFERÊNCIAS}

ABNT. Associação Brasileira de Normas Técnicas, Equipamento Urbano, NBR 9284, 1986.

Associação Brasileira de Normas Técnicas, Execução e Utilização de Passeios Públicos, NB 1338,1990.

Associação Brasileira de Normas Técnicas, Acessibilidade a edificações, mobiliário, espaços e equipamentos urbanos, NBR 9050, 2004.

ALERJ. Assembléia Legislativa do Estado do Rio de Janeiro, Acessibilidade para todos: uma cartilha de orientação. Rio de Janeiro: Núcleo Pró-Acesso, UFRJ/FAU/PROARQ, 2004. 84p.

A PAISAGEM urbana. In: REDAÇÃO ambiente brasil. São Paulo, 2007. Disponivel em: <http://ambientes.ambientebrasil.com.br/urbano/arborizacao_urbana/a_paisagem_urbana.ht $\mathrm{ml}$. Acesso em: 9 jun.2009.

AZEVEDO, J.; GONÇALVES, A. Manual de Boas Práticas em Espaços Verdes. Câmara Municipal de Bragança. Portugal. 174p, 2010.

BRASIL. Constituição da República Federativa do Brasil, de 1988. . Lei no 7.853, de 24 de outubro de 1989. Diário Oficial [da] República Federativa do Brasil, Brasília, DF. 
Decreto no 3.298, de 20 de dezembro de 1999. Diário Oficial [da] República Federativa do Brasil, DF.

. Lei no 10.098, de 19 de dezembro de 2000. Diário Oficial [da] República Federativa do Brasil, Brasília, DF.

Decreto ํo 5.296, de 2 de dezembro de 2004. Diário Oficial [da] República Federativa do Brasil, Brasília, DF.

CEMIG. Companhia Energética de Minas Gerais, Manual de Arborização. Belo Horizonte: Superintendência de Comunicação Social e Representação, 2001. 40 p.

CREA-MG. Conselho Regional de Engenharia, Arquitetura e Agronomia. Guia de Acessibilidade Urbana: fácil acesso para todos. Belo Horizonte, 2006. 96p.

GREY, G.W.; DENEKE, F.J. Urban Forestry. New York, Jonh Wiley, 1978, 279p.

HOLANDA, Da. C. Metodologia para Avaliação da Acessibilidade na Localização de Escolas Públicas do Ensino Fundamental. Fortaleza, 2006. 186p, Dissertação (Mestrado em Engenharia de Transportes) - Universidade Federal do Ceará. Fortaleza, 2006.

IBAM. Manual para implantação de mobiliário urbano na Cidade do Rio de Janeiro. Rio de Janeiro: IBAM/CPU, PCRJ/SMU, 1996. 94p.

LIMA, A. M. Conceito de Meio Ambiente. Ambiente do Meio, 2007. Disponível em: $<$ http://ambientedomeio.com/2007/07/29/conceito-de-meio-ambiente/>. Acesso em: 8 jun. 2009.

MEC - MINISTÉRIO DA EDUCAÇÃO. Revista da Inclusão. Secretaria de Educação Especial. v.1, n.1, out. 2005. Disponível em

<http://portal.mec.gov.br/seesp/arquivos/pdf/revistainclusao1.pdf>. Acesso em 8 jun. 2009.

MELO, F. B. Proposição e Medidas Favorecedoras a Acessibilidade e Mobilidade de Pedestres em Áreas Urbanas. Estudo de Caso: O Centro de Fortaleza. Fortaleza, 2005.

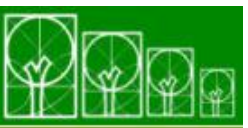


173p, Dissertação (Mestrado em Engenharia de Transportes) - Universidade Federal do Ceará. Fortaleza, 2005.

NAKAYAMA, A. M. Educação Inclusiva: Princípios e Representação. São Paulo, 2007. 353p, Tese (Doutorado) - Universidade de São Paulo. São Paulo, 2007.

ORGANIZAÇÃO DAS NAÇÕES UNIDAS - ONU. Resolução № 217, de 10 de dezembro de 1948. Declaração Universal dos Direitos Humanos.

PREFEITURA DA CIDADE DE SÃO PAULO. Manual Técnico de Arborização Urbana. 2 ed. São Paulo: Secretaria do Verde e do Meio Ambiente, 2005. 45p.

PREFEITURA DA CIDADE DO RIO DE JANEIRO. Rio Cidade o Urbanismo de Volta as Ruas. Rio de Janeiro,1996.

PREFEITURA DE NITERÓI. Conheça Niterói - Educação em números, 2007. 